\title{
NEGOCIAÇÕES RELATIVAS AO COMÉRCIO DE SERVIÇOS NA RODADA URUGUAI DO GATT: semelhanças com a Rodada Doha da OMC
}

\author{
NEGOTIATIONS ABOUT TRADE IN SERVICES AT THE URUGUAI ROUND OF THE GATT: similarities \\ with the Doha Round of WTO
}

\section{Umberto Celli Junior ${ }^{1}$}

\begin{abstract}
Resumo:
A partir da perspectiva dos países em desenvolvimento, principalmente do Brasil, esse artigo procura resgatar a história das negociações sobre o comércio de serviços. Mostra a resistência dos países em desenvolvimento à inclusão do tema na agenda multilateral antes e após o início da Rodada Uruguai do GATT e como o avanço das negociações ficou atrelado à questão agrícola. Nesse contexto, destaca-se o papel do G-10, grupo de países em desenvolvimento liderado por Brasil e Índia, na conformação final do Acordo sobre Serviços da OMC. A atuação do G-10 e as negociações no setor agrícola, durante a Rodada Uruguai, permitem traçar um paralelo entre o papel do G-20, coalizão também liderada por Brasil e Índia, e as negociações sobre serviços na atual Rodada Doha da OMC.

Palavras-chave: Comércio de serviços. Rodada Uruguai. GATT. Negociações no setor agrícola. O papel do G-10 e do G-20. GATS. OMC. Rodada Doha. Países em Desenvolvimento.
\end{abstract}

\begin{abstract}
:
From a developing countries perspective, especially from Brazil's, this article is intended to assess the negotiating history of the trade in services. It shows the developing countries' resistance to have the services sector included in the multilateral agenda both prior and subsequently to the beginning of the GATT Uruguay Round and how the negotiations were tied to the agriculture issue. In this scenario, stands out the role performed by the G-10, a group composed of developing countries under the leadership of Brazil and India, in the final format of the services agreement. The G-10 performance and the negotiations on agriculture in the Uruguay Round allow for a comparison with the role of the G-20, a developing countries coalition also under the leadership of Brazil and India, in the current negotiations on trade in services in the WTO Doha Round.
\end{abstract}

Keywords: Trade in Services. Uruguay Round. GATT. Negotiations on Agriculture. The role of the G-10 and G-20. GATS. WTO. Doha Round. Developing Countries.

Introdução

Durante longo período, as negociações multilaterais no âmbito do Acordo Geral sobre Tarifas Aduaneiras e Comércio (“GATT”) apenas se ocuparam com a liberalização do

1 Professor Doutor do Departamento de Direito Internacional da Faculdade de Direito da Universidade de São Paulo. 
comércio de bens. O comércio de serviços era visto como matéria afeita aos interesses internos dos Estados, sujeita, portanto, a regulamentação no plano doméstico. Isso se deveu, em larga medida, àquilo que Carreau e Juillard denominam de "especificidade fundamental” do comércio de serviços, o que o torna profundamente diferente do comércio de bens. ${ }^{2}$

Enquanto um contrato de venda de mercadorias, seja interno ou internacional, implica uma transferência de propriedade da coisa vendida ao comprador, a prestação de serviços, por sua natureza freqüentemente imaterial ou intangível, revela-se muito mais complexa. ${ }^{3} \mathrm{O}$ fornecimento ou a prestação de um serviço envolve, usualmente, obrigações de fazer e de não-fazer, sem que haja a transferência de propriedade de um bem, como, por exemplo, um contrato de seguros ou de transporte. O objeto do pertinente contrato é a própria prestação do serviço, o que resulta em obrigações recíprocas que vão se estender no tempo e, por vezes, por longo período.

Além disso, o setor de serviços como um todo é extraordinariamente vasto, abrangente e constituído de mais de uma centena de subsetores específicos e variados, tais como intermediação financeira, comunicações, distribuição, hotéis e restaurantes, educação, saúde, construção, dentre outros.

A complexidade e a "especificidade fundamental" do setor sempre dificultaram a própria conceituação do comércio de serviços. Para Jackson, talvez a maior e mais importante dificuldade seja a questão de se aplicar ao comércio de serviços o princípio econômico de "vantagem comparativa", tal como é aplicado no comércio de bens. Apesar de não estar plenamente convencido, acredita ser apropriada essa aplicação, principalmente tendo em conta o fato de que a concorrência entre provedores de serviços tende a aumentar a eficiência e a reduzir o custo dos serviços da mesma forma que ocorre no comércio de bens. ${ }^{4}$

Outra questão conceitual não menos complicada consiste em saber se os conhecidos e consolidados princípios do comércio de bens, tais como o da nãodiscriminação, consubstanciado na cláusula de nação mais favorecida, o do tratamento

2 CARREAU, Dominique; JUILLARD, Patrick. Droit International Économique. 4. ed. Paris: L.G.D.J, 1998. p. 313.

3 Nesse sentido, como também assinalam Aaditya Mattoo e Robert Stern, à diferença do comércio de bens, serviços são freqüentemente intangíveis, invisíveis e perecíveis, além de requererem usualmente a simultaneidade da produção e do consumo. Ver MATTOO, Aaditya e STERN, Robert. Trade in Services - Introduction and Overview. In: TRADE in Services Handbook. Washington: World Bank, p. 5 (material em preparação tornado disponível durante o "Trade in Services Internet Course", realizado de 25 de setembro a 30 de novembro de 2006).

4 Cf. JACKSON, John H. The World Trading System - law and policy of International Economic Relations. 2. ed.. Cambridge: the MIT Press, 2002. p. 306-307. 
nacional e os de acesso a mercados com concessões reciprocamente negociadas, aplicarse-iam por analogia ao comércio de serviços. O princípio do tratamento nacional seria particularmente problemático, já que alguns tipos de serviços requerem a adoção de políticas governamentais específicas de proteção aos provedores nacionais em face dos riscos trazidos pela importação. Seria o caso, por exemplo, dos serviços financeiros e a necessidade de se protegerem consumidores por meio das denominadas normas governamentais prudenciais.

Estender o conceito de tratamento nacional aos serviços, ressalta Jackson, "requereria um conhecimento considerável sobre determinado setor em particular, o que redundaria em modificações necessárias aos conceitos básicos de tratamento nacional de forma a equilibrar efetivamente a necessidade de liberalização comercial com apropriadas políticas nacionais prudenciais e de regulação relacionadas a esses setores, tais como, bancos, seguros, serviços de corretagem, e assim por diante". ${ }^{5}$

Assim é que, somente a partir da década de 60, em face do notável crescimento do comércio internacional de serviços, impulsionado sobretudo pelos avanços tecnológicos na área de telecomunicações, o setor acabou sendo colocado no centro das atenções de corporações multinacionais, especialmente as do setor financeiro e de informática. A ausência de regulamentação no plano multilateral e as restrições de acesso a mercados existentes na grande maioria dos países impediam, no entanto, sua maior expansão. Vários grupos de prestadores de serviços de países desenvolvidos começaram, então, a pressionar seus governos a buscar alguma forma de mecanismo internacional que pudesse auxiliar na remoção ou redução dessas restrições e barreiras. ${ }^{6}$

O Governo norte-americano foi o primeiro a tomar a iniciativa de propor o tema comércio de serviços nas negociações multilaterais do GATT. Tal inovação, diz Ciro

\footnotetext{
5 Tradução livre do autor para o seguinte trecho do original: “...to apply a national treatment concept to services required considerable expertise about particular service sectors, and this could result in changes needed to the basic concepts of national treatment so as to effectively balance the need for trade liberalization against appropriate national government regulatory and prudential policies related to the particular service sectors - banking, insurance, brokerage, and so on". JACKSON, John H. The World Trading System - law and policy of International Economic Relations. 2. ed. Cambridge: the MIT Press, 2002. p. 307.

6 Jackson sublinha que, “ao vislumbrar a perspectiva de expandir seus negócios para outros países, esses grupos de prestadores de serviços depararam com medidas governamentais desses países restritivas à importação com o objetivo de preservar o mercado para prestadores de serviços nacionais. Assim, começaram a clamar por um mecanismo de cooperação internacional que pudesse criar regras impeditivas dessa atividade protecionista antes que essas atividades se multiplicassem e se transformassem em trincheiras". Tradução livre do autor para o seguinte trecho do original: "Some service providers were exploring the possibility of exporting their activity, and they had begun to encounter foreign government actions designed to restrict their activity and to preserve businesses for domestic service providers in those importing countries. Thus, various groups began to urge an international cooperative mechanism that would develop rules against such protectionist activity before those activities became entrenched and multiplied". Cf. JACKSON, John H. op. cit., p. 306.
} 
Cunha, "teria tido como importante fator a pressão de empresas do setor terciário, que iniciaram mobilização, na década de 1970, para demonstrar a importância econômica dos serviços e para colocá-la na mesa de negociações multilaterais". De qualquer forma, prossegue, "pouco se alcançou nesse âmbito durante a Rodada Tóquio; a década de 1980 presenciaria a maior obstinação americana pela inclusão dos serviços nas negociações multilaterais de liberalização comercial"?

Muito embora essa obstinação tenha resultado na inclusão do tema serviços na Rodada Uruguai, em 1986, as negociações progrediram muito lentamente. Isso, não-só pela complexidade e "especificidade fundamental" do setor, como também em virtude dos constantes impasses decorrentes das negociações relativas à agricultura.

O objetivo deste artigo é, pois, o de fazer uma breve análise da evolução das negociações do comércio de serviços, a partir de 1980, até o final da Rodada Uruguai, em 1994, com o estabelecimento, no quadro normativo da Organização Mundial do Comércio (“OMC"), do Acordo Geral sobre o Comércio de Serviços (“GATS”). Essa análise permitirá verificar certas semelhanças com alguns dos obstáculos daquele período que subsistem na atual Rodada Doha da OMC.

\section{Discussões e Negociações antecedentes à Rodada Uruguai}

Em 1980, os Estados Unidos acabaram, finalmente, persuadindo a Organização para Cooperação e Desenvolvimento Econômico (“OCDE”) a realizar novos estudos acerca do comércio de serviços. ${ }^{8}$ Esses estudos revelaram não-somente o grande potencial do setor, como também o alto grau de protecionismo dos países. Além disso, no mesmo período, o GATT constituiu um Grupo Consultivo composto de dezoito Partes Contratantes com o objetivo de analisar um documento preparado pelo Secretariado acerca das relações entre alguns serviços e o comércio de bens.

Apesar de esse grupo ter concluído haver pontos essenciais de ligação entre o comércio de bens e alguns serviços e que, portanto, este último deveria ser abrangido pelo GATT, muitas Partes Contratantes se opuseram a essa idéia. Alguns países se preocupavam

7 CUNHA, Ciro Leal M. da. A introdução do comércio de serviços na regulação multilateral do comércio: breve histórico. In: CELLI JUNIOR, Umberto (Org.). Comércio de serviços na OMC. Curitiba: Juruá, 2005. p. 23-24.

8 Estudo anterior havia sido feito por um grupo de peritos convocados pela OCDE, em 1972, "para examinar as perspectivas comerciais a longo prazo dos Estados-Membros, em face das transformações estruturais das sociedades industrializadas". No relatório desse grupo, a expressão "comércio de serviços", que aparecia pela primeira vez, foi utilizada em substituição às "transações com invisíveis". Ver a respeito MERCADANTE, Araminta de Azevedo. Harmonização em matéria de serviços e investimentos. In: CASELLA, Paulo Borba; MERCADANTE, Araminta de Azevedo (Org.). Guerra comercial ou integração mundial pelo comércio? O Brasil e a OMC. São Paulo: LTr, 1996. p. 414. 
com a complexidade dos serviços e a existência de outras organizações internacionais, cujas funções já cobriam importantes setores de serviços; outros entendiam que qualquer avanço nessa área seria prematuro e duvidavam da viabilidade de se estender o GATT aos serviços. ${ }^{9}$

Na Conferência Ministerial do GATT, de 1982, os Estados Unidos, apoiados, como relata Araminta Mercadante, por poderoso lobby de grandes empresas prestadoras de serviços daquele país, representadas pela Coalition of Service Industries, conseguiram incluir na pauta o tema relativo a serviços. O objetivo do lobby, afirma a Autora, "era simples: a liberalização completa do comércio internacional de serviços no seu sentido mais amplo, ou seja, a liberdade de produzir e de vender serviços em todos os países do mundo, sem quaisquer restrições, o que levaria a uma desregulamentação dos serviços em escala planetária". ${ }^{10}$

Para Bernard Hoekman e Aaditya Mattoo, a resposta inicial da maioria dos países à proposta norte-americana foi de cautela (guarded), ${ }^{11}$ muito embora alguns países desenvolvidos, com destaque para o Japão, começassem a esboçar um apoio mais explícito. ${ }^{12}$ Já os países em desenvolvimento mantiveram-se contrários à inclusão do tema nas negociações multilaterais, pois temiam que a imposição da abertura de seus mercados internos em troca de maior acesso aos mercados de bens dos países desenvolvidos acabasse por legitimar, na expressão de Araminta Mercadante, "uma inaceitável divisão internacional do trabalho, em que os países desenvolvidos teriam o domínio do comércio internacional de serviços e das novas tecnologias, excluindo países periféricos". ${ }^{13}$

Os países em desenvolvimento também discordavam do fato de os Estados Unidos pretenderem tratar do "direito ao estabelecimento" no futuro acordo, o que abrangeria o movimento de capital para investimento direto. Extrapolar-se-ia, assim,

\footnotetext{
9 Ver a respeito STEWART, Terence. P. The Uruguay Round: a negotiating history 1896-1992. Nova York: Aspen Publishers, 1996. v. 2, p. 2.345.

${ }^{10}$ MERCADANTE, Araminta de Azevedo. Harmonização em matéria de serviços e investimentos. In: CASELLA, Paulo Borba; MERCADANTE, Araminta de Azevedo (Org.). Guerra comercial ou integração mundial pelo comércio? O Brasil e a OMC. São Paulo: LTr, 1996. p. 415. Os Estados Unidos também pleiteavam a inclusão dos temas investimentos e propriedade intelectual, os quais, juntamente com serviços, eram chamados de novos temas.

11 HOEKMAN, Bernard e MATTOO, Aaditya. Services, Economic Development and the Doha Round: Exploiting the Comparative Advantage of the WTO. Centre for Economic Policy Research (CEPR) - Discussion Paper Series No. 5628, abril de 2006, p. 01. Disponível em: <http://www.cepr.org/pubs/dps/DP5628.asp>. Acesso em: 03 maio 2007.

12 CUNHA, Ciro Leal M. da. op. cit., p. 24. Os Estados-membros das Comunidades Européias, sobretudo a França, tampouco receberam com entusiasmo a iniciativa norte-americana, já que ela acenava com a inclusão na agenda de questões prioritárias para os países em desenvolvimento, como a agricultura.

${ }^{13}$ MERCADANTE, Araminta de Azevedo. op. cit., p. 415.
} 
o âmbito estrito do comércio para abordar-se a sensível questão dos investimentos estrangeiros. Temas de maior interesse, tais como o comércio de bens agrícolas e têxteis, nos quais tinham vantagens comparativas, e a questão do "tratamento especial e diferenciado", não-resolvidos nas rodadas anteriores, continuavam pendentes. ${ }^{14}$

Sustentavam ainda, com destaque para o Brasil, a necessidade de reforma das disposições do GATT para que novos temas pudessem ser incluídos. A estratégia aqui era muito clara: ao defender a reforma, a probabilidade de inclusão desses novos temas seria muito reduzida, uma vez que havia a necessidade do consenso das Partes Contratantes. Por fim, uma outra razão que, a exemplo do comércio de bens agrícolas e do "tratamento especial e diferenciado", permanece atual: o desconhecimento técnico a respeito do assunto, principalmente por parte dos países menos desenvolvidos ("LDCs").

Se, de um lado, da Conferência Ministerial não resultou o lançamento de uma nova rodada de negociações, de outro, foi acordada a inclusão do tema serviços (e de outros como propriedade intelectual) quando essa rodada viesse a ocorrer. A pressão feita pelos Estados Unidos para que se chegasse a esse acordo foi, sem dúvida, muito grande. Como boa parte dos países em desenvolvimento, Brasil inclusive, atravessava um período de grave crise financeira, dependendo, portanto, de recursos de instituições sob forte influência americana como o FMI, não foi possível resistir a essa pressão. Mesmo tendo concordado com a inserção do tema serviços na agenda de negociações, o Brasil, ainda que de forma meramente retórica, reafirmou sua posição contrária.

Por meio da Declaração Ministerial, de 1982, as Partes Contratantes acordaram o seguinte: (i) recomendar a cada Parte Contratante, com interesse em serviços de diversos tipos, a realização, na medida do possível, de uma pesquisa nacional sobre as questões envolvendo o setor; (ii) convidar as Partes Contratantes a trocar informações, inclusive por meio do GATT e de outras organizações internacionais, devendo ser a compilação e a distribuição dessas informações baseadas em um formato uniforme; e

\footnotetext{
${ }^{14}$ CUNHA, Ciro Leal M. da. A introdução do comércio de serviços na regulação multilateral do comércio: breve histórico. In: CELLI JUNIOR, Umberto (Org.). Comércio de serviços na OMC. Curitiba: Juruá, 2005. p. 25. Ver também MARCONINI, Mário. O acordo geral sobre o comércio de serviços: O Conceito e o Regime. In: AMARAL JÚNIOR, Alberto do. OMC e o Comércio Internacional. Aduaneiras: São Paulo, 2002. p. 89-90. O Brasil e outros países em desenvolvimento assumiram, conforme relato de Marcelo de Paiva Abreu, "uma postura defensiva nas conversas que precederam o encontro ministerial do GATT em 1982, tentando obstruir a inclusão da TRIPS, do TRIMS, e, especialmente, dos serviços na agenda provisória da rodada seguinte de negociações. Essa oposição fundamentava-se no receio de que a inclusão de novos itens iria desviar a atenção das negociações pendentes sobre acesso a mercados de um modo geral, mas sobretudo de têxteis e agricultura, o que era de especial interesse para a maioria das economias em desenvolvimento." Ver ABREU, Marcelo de Paiva. O Brasil, o GATT e a OMC: história e perspectivas. Política Externa, Rio de Janeiro, v. 09, n. 04, p. 92, mar./maio 2001.
} 
(iii) examinar e debater os resultados dessas pesquisas, bem como as informações e os comentários formulados por outras organizações internacionais em suas reuniões, de 1984, considerando a adequação e a oportunidade de qualquer ação multilateral acerca do tema. ${ }^{15} \mathrm{O}$ propósito dessas pesquisas e desses estudos seria o de "determinar o status quo dos setores de serviços e as conseqüências potenciais da aplicação das regras do GATT ao seu comércio". ${ }^{16}$

Enquanto treze estudos e pesquisas foram apresentados por países desenvolvidos, dentre os quais Estados Unidos, Canadá, Japão, Reino Unido, Suíça, Holanda, Dinamarca e Suécia, os LDCs e boa parte dos países em desenvolvimento recusaram-se a apresentá-los em face de sua relutância em ter o comércio de serviços regulamentado no plano multilateral. Esses estudos e pesquisas demonstraram em geral que: (i) faltava ainda uma definição mais clara sobre comércio de serviços; (ii) os dados disponíveis sobre esse comércio eram incompletos; (iii) muitos setores de serviços, tais como o financeiro, o de comunicações e o de transportes eram fortemente regulamentados e a grande variedade de regulamentação adotada por diferentes países dificultava a abertura do setor; (iv) uma ampla gama de barreiras comerciais, tais como restrições de acesso a mercado, limitações quanto à condução de negócios por empresas estrangeiras e medidas restritivas à circulação de moedas, impedia o comércio de serviços; e (v) a importância do setor de serviços requeria uma reavaliação de seu papel na formulação de políticas comerciais.

Os Estados Unidos e o Reino Unido foram os mais enfáticos no tocante à necessidade de se criar um quadro multilateral similar ao do GATT para o comércio de serviços. Os Estados Unidos ressaltaram em seu relatório que, caso não se chegasse a um consenso sobre a criação desse quadro, o comércio de serviços acabaria sendo regulado por acordos regionais ou bilaterais em detrimento do sistema multilateral. ${ }^{17}$

\footnotetext{
15 Tradução livre do autor do seguinte trecho da Conferência Ministerial de 1982, reproduzido em STEWART, Terence. P. The Uruguay Round: a negotiating history 1896-1992. Nova York: Aspen Publishers, 1996. v. 2, p. 2.346: "1. To recommend to each contracting party with an interest in services of different types to undertake, as far as it is able, national examinations of the issues in this sector. 2. To invite contracting parties to exchange information on such matters among themselves, inter alia, through international organizations such as GATT. The compilation and distribution of such information should be based on as uniform a format as possible. 3. To review the results of these examinations, along with the information and comments provided by relevant international organizations, at their 1984 Session and to consider whether any multilateral action in these matters is appropriate and desirable".

16 CUNHA, Ciro Leal M. da. op. cit., p. 27.

17 Ver STEWART, Terence. P. The Uruguay Round: a negotiating history 1896-1992. Nova York: Aspen Publishers, 1996. v. 2, p. 2.347-2.348.
} 
Em abril de 1985, a OCDE manifestou-se amplamente favorável à abertura de uma nova rodada de negociações no GATT que abrangesse o comércio de serviços. Liderado por Brasil e Índia, um grupo do qual também faziam parte Argentina, Egito e Peru, dentre outros, que passou a ser identificado como Grupo dos Dez (G-10), apresentou ao Conselho do GATT um documento em que expressava sua concordância quanto à abertura de uma nova rodada, desde que observadas algumas condições. Uma dessas condições era justamente a de que o tema serviços ficasse fora das negociações. Como ponderado por Paiva Abreu, o G-10 seria, na prática, um G-2 entre Brasil e Índia com o claro objetivo de barrar novos temas, adotando como uma de suas táticas a exploração de divergências entre os países desenvolvidos, tais como as existentes entre os Estados Unidos e as Comunidades Européias relativamente à questão agrícola. ${ }^{18}$

Em julho de 1986, o Brasil, em nome do G-10, apresentou, como documento formal, ao Comitê Preparatório da Rodada, minuta de Declaração Ministerial observando que "os objetivos de liberalização e eliminação de distorções deveriam ser perseguidos por meio de uma rodada multilateral de negociações no setor do comércio de bens" ${ }^{19}$ Nenhuma menção foi feita ao comércio de serviços. Por sua vez, a Suíça, em sua proposta de minuta que foi apoiada por vários países, dentre os quais, Áustria, Chile, México e Estados Unidos, propugnou pelo estabelecimento de um quadro multilateral de princípios e regras para o comércio de serviços que pudesse permitir às Partes Contratantes decisão posterior quanto sua inserção ou-não no sistema GATT.

Apesar desse antagonismo de posições, alguns meses depois, a Rodada Uruguai foi lançada com a inclusão do tema serviços. Nos termos da Declaração Ministerial firmada em Punta del Este, as negociações sobre o comércio de serviços teriam por objetivo.

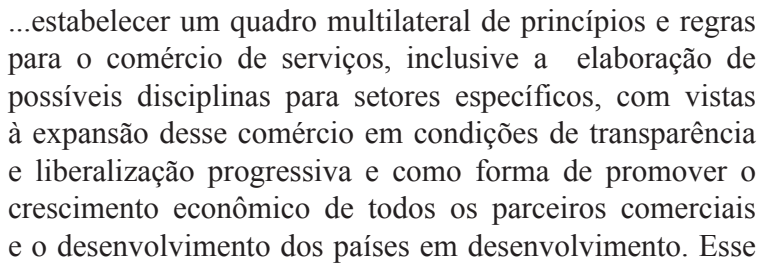

18 ABREU, Marcelo de Paiva. O Brasil na Rodada Uruguai do GATT: 1982-1993. In: FONSECA JÚNIOR, Gelson; NABUCO DE CASTRO, Sérgio Henrique. Temas de política externa brasileira II. 2. ed. São Paulo: Paz e Terra, 1997. v. 1, p.350.

19 Tradução livre do autor do seguinte trecho da minuta de Declaração Ministerial: “...aims of liberalization and elimination of distortions should be pursued through a round of multilateral trade negotiations in the area of trade in goods". Preparatory Committee - Record of Discussions - Discussions of 8-31 July 1986, GATT Doc. No. PREP.COM (86) W 41 (June 23, 1986). (STEWARD, Terence P. op. cit., p. 2.357). 
quadro deverá respeitar os objetivos de políticas de leis e regulamentos nacionais concernentes a serviços, bem como deverá levar em consideração o trabalho de organizações internacionais relevantes. ${ }^{20}$

As negociações atinentes ao tema deveriam ser, porém, realizadas separadamente das relativas ao comércio de bens, ${ }^{21}$ ou seja, os "serviços seriam negociados no âmbito da Rodada Uruguai, mas fora do quadro jurídico do GATT, ficando estabelecido um Grupo de Negociações sobre Serviços, no nível ministerial, juridicamente distinto dos demais grupos negociadores". ${ }^{22}$ Esse mecanismo de negociação batizado de dual track, que tornou evidente a solução de compromisso a que chegaram as Partes Contratantes, endereçava, de certa forma, as aspirações de países como Brasil e Índia, à medida que lhes permitiria, em tese, suportar as pressões para concessões cruzadas entre os temas pendentes e serviços. Bloquear concessões no setor de serviços era de importância estratégica para esses países, uma vez que o balanço potencial de tais concessões favorecia supostamente os países desenvolvidos. ${ }^{23}$

\section{As Negociações na Rodada Uruguai: o impasse de Bruxelas (1990)}

Dois grupos foram compostos para supervisionar as negociações: o Grupo de Negociações de Bens e o Grupo de Negociações de Serviços (“GNS”). O GNS identificou, desde logo, um grande número de itens que precisariam ser objeto de negociação, dentre os quais: (i) definições e estatísticas; (ii) amplos conceitos nos quais os princípios e as regras sobre serviços, inclusive possíveis disciplinas para setores específicos, deveriam se basear; (iii) cobertura do quadro multilateral para o comércio de serviços; (iv) acordos e disciplinas internacionais já existentes; e (v) medidas e práticas que contribuíssem para

\footnotetext{
20 Tradução livre do autor do seguinte de trecho da Declaração de Punta del Este: [Negotiations in this area shall] "aim to establish a multilateral framework of principles and rules for trade in services, including an elaboration of possible disciplines for individual sectors, with a view to expansion of such trade under conditions of transparency and progressive liberalization and as a means of promoting economic growth of all trading partners and the development of developing countries. Such framework shall respect the policy objectives of national laws and regulations applying to services and shall take into account the work of relevant international organizations". Reproduzido em STEWART, Terence. P. The Uruguay Round: a negotiating history 18961992. Nova York: Aspen Publishers, 1996. v. 2, p. 2.359.

${ }^{21}$ O tema serviços foi incluído na Parte II da Declaração de Punta del Este, ao contrário dos outros temas, inseridos na primeira parte. Como ressaltado por Marconini, isso foi feito "como forma de separá-lo de outros assuntos e não prejulgar o futuro das negociações sobre questões institucionais.” Afinal, diz ele, o comércio internacional no setor terciário "houvera sido a causa de bastante truculência e hesitação, que explicava o porquê de sua separação formal de outros assuntos tratados pela oitava rodada de negociações do Gatt". MARCONINI, Mário. op. cit., p. 83.

22 MERCADANTE, Araminta Azevedo de. op. cit., p. 417.

${ }^{23}$ Ver CUNHA, Ciro Leal M. da. op. cit., p. 29.
} 
a expansão ou limitação do comércio de serviços, especificamente quaisquer barreiras apontadas pelas partes às quais as condições de transparência e de liberalização progressiva pudessem ser aplicáveis.

Uma significativa divergência de posições entre as partes dificultou o avanço inicial das negociações, principalmente com relação a quatro pontos fundamentais, a saber: (i) deveria o acordo resultante das negociações cobrir todos os setores de serviços ou apenas alguns com a expectativa de uma negociação futura para tratar dos que ficassem de fora?; (ii) deveria o acordo sobre serviços ter estrutura similar à do GATT e conter as mesmas obrigações e princípios daquele acordo de tarifas? Em caso afirmativo, os princípios, as regras e os conceitos que se aplicavam ao comércio de bens seriam apropriados para regular o comércio de serviços?; (iii) qual seria a melhor definição para serviços? Com que rapidez deveriam as partes assumir todas ou algumas das obrigações do acordo? Deveria haver exceções às obrigações? Deveria haver a possibilidade de relação cruzada com o comércio de bens, inclusive no tocante a sanções?; e (iv) qual seria a melhor forma de se assegurar um aumento da participação dos países em desenvolvimento no sistema comercial internacional e endereçar as necessidades especiais desses países ${ }^{24}$

Os Estados Unidos tinham, naturalmente, uma perspectiva bastante liberal para o acordo de serviços. Em 1985, haviam celebrado com Israel um Tratado de Livre Comércio com o firme propósito de incluir a liberalização desse setor no contexto de uma negociação comercial. Subseqüentemente, firmaram o Tratado de Livre Comércio com o Canadá (1987), cujo modelo de liberalização foi, segundo assinala Pierre Sauvé, o que mais diretamente inspirou as negociações multilaterais que tiveram início na Rodada Uruguai. $^{25}$

Em sintonia com essa visão liberal, sustentavam os negociadores daquele país que a regra do tratamento nacional deveria ser geral e vinculativa (i.e., com obrigações gerais vinculativas e cobertura de todos os setores) e a da nação mais favorecida aplicável a todas as Partes Contratantes. O comércio de serviços deveria ser definido de forma bastante ampla para poder compreender, inclusive, os investimentos estrangeiros diretos. Desejavam, enfim, uma redução substancial de todas e quaisquer medidas restritivas de acesso a mercados.

\footnotetext{
${ }^{24}$ Ver STEWART, Terence. P. The Uruguay Round: a negotiating history 1896-1992. Nova York: Aspen Publishers, 1996. v. 2, p. 2.360.

${ }^{25}$ SAUVÉ, Pierre. Been There, Not [Quite] [Yet] Done That: Lessons and Challenges in Services Trade. In: NCCR Trade Working Paper. Disponível em <http://www.nccr-trade.org> Acesso em: 01 maio 2007.
} 
Muito embora as Comunidades Européias também fossem favoráveis a uma ampla definição do comércio de serviços, entendiam que as negociações de liberalização não deveriam ser realizadas de forma geral, mas, por setor, inclusive no tocante à regra do tratamento nacional, assumindo, portanto, um viés mais defensivo que os americanos.

O Brasil mantinha-se refratário à idéia de concessões no setor de serviços. No entanto, passou a emitir sinais de maior pragmatismo, pois elas poderiam servir de moeda de troca (trade off) durante as negociações de outros temas de seu interesse. Essa nova postura devia-se, em grande parte, a alterações que ocorriam no cenário econômico internacional, como o esgotamento do modelo de substituição de importações, o que levou muitos países emergentes a dar início, com maior ou menor intensidade, a um processo de abertura de seus mercados.

Na Reunião de Meio Percurso de Montreal (Mid-term Review), de 1988, ${ }^{26}$ constatou-se que as negociações tinham avançado muito pouco. O travamento das negociações era determinado pela continuidade da divisão de posições relativamente a outros temas, além de serviços, tais como, propriedade intelectual, investimentos, têxteis e agricultura, dentre outros. Notaram-se, inclusive, desavenças entre os Estados Unidos e as Comunidades Européias no tocante à agricultura. Para as Comunidades Européias, a proposta de liberalização para aquele setor apresentada pelos Estados Unidos, que consistia na eliminação de subsídios distorcivos ao comércio internacional no prazo de dez anos, era inaceitável.

Curiosamente, o Brasil e outros países latino-americanos do Grupo de Cairns, que haviam iniciado bem-sucedidas gestões para bloquear os resultados das negociações de vários grupos de trabalho, acabaram sendo apoiados pelos Estados Unidos, os quais passaram a condicionar a consolidação da rodada a avanços na área agrícola. Por outro lado, a postura mais flexível do Brasil com relação aos novos temas, especialmente os aspectos dos Direitos de Propriedade Intelectual relacionados ao comércio ("TRIPS"), gerava, na expressão de Paiva Abreu, "maior convergência com a posição estadunidense sobre liberalização agrícola, via Cairns". ${ }^{27}$

Apesar do pouco avanço nas negociações, já era possível vislumbrar certo consenso em torno da criação de um mecanismo separado do GATT que pudesse resultar em um acordo específico sobre serviços. Contudo, foi somente durante as negociações

\footnotetext{
${ }^{26}$ A Reunião de Meio Percurso havia sido convocada para realizar-se uma avaliação do andamento das negociações a exatamente dois anos do prazo originalmente previsto para o término da Rodada (1990).

27 Ver ABREU, Marcelo de Paiva. O Brasil, o GATT e a OMC: história e perspectivas. Política Externa, Rio de Janeiro, v. 9, n. 4, p. 105, mar./maio 2001.
} 
realizadas em setembro de 1989 que, virtualmente, todos os participantes concordaram com a necessidade de um acordo geral sobre o comércio de serviços, o GATS, a ser estabelecido de forma separada, mas, em linha com o GATT. ${ }^{28}$

Antes da Reunião de Bruxelas, de 1990, que deveria marcar o término das negociações da Rodada, as posições de Brasil e Índia, que encabeçavam o G -10, e as da OCDE pareciam convergir em alguns pontos. Contudo, o projeto do acordo encontravase bastante incompleto, faltando "clareza até mesmo com relação a quais princípios de liberalização se aplicariam a comércio de serviços" ${ }^{29}$ Aliás, o próprio texto desse projeto continha o reconhecimento de que temas essenciais estavam pendentes de acordo, incluindo conceito, abrangência, mobilidade de trabalho, tratamento especial para os LDCs e aplicabilidade da cláusula de nação mais favorecida, dentre outros.

Mas, o fator determinante para o malogro das negociações foi, mais uma vez, a agricultura. A polarização entre Estados Unidos, que propunham corte de $75 \%$ e $90 \%$ nos subsídios domésticos e à exportação, respectivamente, e Comunidades Européias, que aceitavam apenas $30 \%$ em ambos, impediu a conclusão da Rodada. ${ }^{30}$

Vários esforços foram feitos para que as negociações sobre serviços fossem retomadas no início do ano seguinte, 1991, pois, para muitos negociadores, a sensação era de que o fracasso na elaboração da moldura do GATS poderia levar os países a buscar acordos bilaterais ou regionais. Não-obstante esses esforços, nada poderia ser feito enquanto não se resolvesse o impasse das negociações agrícolas. ${ }^{31}$

\footnotetext{
28 "...would be established separate from, but in tandem with, the GATT". Cf. STEWART, Terence. P. The Uruguay Round: a negotiating history 1896-1992. Nova York: Aspen Publishers, 1996. v. 2, p. 2.362.

${ }^{29}$ Ver MARCONINI, Mário. op. cit., p. 90.

${ }^{30}$ ABREU, Marcelo de Paiva. O Brasil, o GATT e a OMC... cit., p. 95. O Autor lembra ainda que o Brasil e outros países latino-americanos, ao contrário da Ásia, consolidaram "todas as suas tarifas: $35 \%$ para produtos industriais e até $55 \%$ para produtos agrícolas. Antes da Rodada Uruguai, somente $23 \%$ das importações estavam nas linhas tarifárias consolidadas e somente $6 \%$ das linhas eram consolidadas." O encontro de Bruxelas marcou, assim, "a consolidação da transição brasileira para uma agenda positiva nas negociações. Outra vez, o país desempenhava seu papel na negociação da liberalização agrícola. O fracasso de Bruxelas, onde se planejara o encontro final da rodada, teve a vantagem de dar mais tempo ao Brasil para alterar sua política com vistas a uma agenda mais concreta." (p. 106/107). Steward também enfatiza que "as negociações foram interrompidas como resultado do impasse criado na questão da agricultura, especialmente no tocante à manutenção de subsídios mantidos pela Europa como parte de sua Política Agrícola Comum (PAC). Esse impasse redundou no colapso das negociações da Rodada Uruguai em 07 de dezembro de 1990.” Tradução livre do autor para o original: "All negotiations ground to a halt, however, as a result of the deadlock that developed over agriculture issues, in particular subsidies maintained by Europe as part of their Common Agricultural Policy (CAP). The deadlock resulted in the collapse of the Uruguay Round negotiations on December 7, 1990". Cf. STEWARD, Terence P. op. cit, p. 2.395.

31 Todavia, como acentuado por Dominique Carreau e Patrick Juillard, "as negociações continuariam, tanto que o Congresso dos Estados Unidos haviam aceitado prorrogar a delegação de poder concedida ao Presidente para concluir um acordo comercial global", tradução livre do autor para o original: "Toutefois, les négociations
} 


\section{O “Draft Final Act” ou "Dunkel Draft” (1991)}

No final de 1991, o então diretor-geral do GATT, Arthur Dunkel, fez circular em Genebra a minuta de um texto de acordo que cobria todas as áreas de negociação intitulada "Minuta da Ata Final que Incorpora os Resultados da Rodada Uruguai de Negociações Comerciais Mulilaterais" ("Draft Final Act Embodying the Results of the Uruguay Round of Multilateral Trade Negotiations"), que ficou conhecida como "Dunkel Draft". ${ }^{32}$ Como um documento destinado a constituir uma representação concreta e abrangente do pacote global dos resultados da Rodada Uruguai, a expectativa era de que fosse aceito em sua totalidade (com pequenos ajustes) como um acordo final ou que servisse de base para intensas e decisivas negociações que pudessem rapidamente levar à conclusão da Rodada.

A proposta de acordo relativa a serviços no "Dunkel Draft" continha trinta e quatro artigos e alguns anexos sobre setores específicos, tais como serviços financeiros, de telecomunicações e de transporte. Trazia uma série de obrigações básicas, bem como dispositivos acerca do mecanismo de liberalização progressiva, de compromissos relacionados a um cronograma das medidas adicionais de liberalização, de acesso a mercados, do princípio do tratamento nacional e de exceções à aplicação da cláusula de nação mais favorecida. $\mathrm{O}$ "Dunkel Draft" não incluía, no entanto, listas de compromissos de liberalização. Somente no final de 1992, "o GATS seria de fato concluido e, com ele, 108 listas de compromissos de liberalização de todos os países participantes da Rodada Uruguai". ${ }^{33}$

O Acordo de "Blair House" de 1992

Os dois últimos anos de negociações continuaram sendo marcados predominantemente pelo impasse sobre a questão agrícola entre Estados Unidos e

continuèrent, le Congrès des Etats-Unis ayant accepté de prolonger la délégation de pouvoir accordée au Président pour conclure un accord commercial global". Ver CARREAU, Dominique; JUILLARD, Patrick. Droit International Économique. 4. ed. Paris: L.G.D.J., 1998. p. 118.

${ }^{32} \mathrm{O}$ "Dunkel Act" representou um marco histórico nas negociações, apesar de ter suscitado justificadas suspeitas dos países em desenvolvimento por não ser exatamente o resultado de um acordo ou consenso entre as Partes Contratantes do GATT, mas uma proposta de seu Diretor-Geral, ou seja, uma medida de cima para baixo. Ao noticiar o falecimento de Arthur Dunkel em 2005, a OMC assim se pronunciou: "O profundo conhecimento de aspectos técnicos e a diplomacia perspicaz de Dunkel transformaram milhares de páginas de propostas diversas e muitas vezes conflitantes em um único documento de cerca de 500 páginas, preparando a essência da futura OMC". "Mr Dunkel's deep understanding of the technical issues combined with his shrewd diplomacy transformed hundreds of thousands of pages of diverse, often conflicting, proposals into a manageable single document of some 500 pages, distilling the essence of the future WTO.” [tradução livre do autor]. Disponível em: <http://www.wto.org/English/news_e/pres05_e/pr409_e.htm>. Acesso em: 11 jul. 2007.

${ }^{33}$ MARCONINI, Mário. op. cit., p. 91. 
Comunidades Européias. No tocante a serviços, também permaneciam as divergências entre o G-10 e a maior parte dos países desenvolvidos. O Acordo de "Blair House", ${ }^{34}$ celebrado em Washington, em 1992, que, no início, teve a oposição da França, ${ }^{35}$ além de, finalmente, resultar na inclusão da agricultura no âmbito do GATT, abriria o caminho para que se chegasse a uma convergência em serviços.

Com relação a serviços, os pontos mais controversos, como serviços audiovisuais, financeiros, marítimos e aéreos, acabaram, como ressalta Ciro Cunha, sendo excluídos "de facto" do acordo, ${ }^{36}$ o que permitiria, enfim, a conclusão do GATS. Como salienta Marconini, a conclusão de um acordo sobre o comércio de serviços confirmou "que a heterogeneidade dos setores não impedia a criação de um conjunto de regras e princípios comuns para todos. Demonstrou que acordos internacionais, setoriais ou bilaterais existentes não eram necessariamente incompativeis com as disciplinas de liberalização do comércio". Revelou, por fim, diz ele, "que separar o tema do sistema multilateral do comércio, em lugar de incluído no mesmo regime de regras, negociações e solução de controvérsias, não fazia sentido prático". ${ }^{37}$

\section{A Conclusão da Rodada Uruguai e o GATS (1994)}

Como ressaltado por Araminta Mercadante, a introdução de serviços no âmbito do GATT prevaleceu em virtude de sua importância para o comércio internacional. O GATS, parte do quadro jurídico da então criada organização internacional de cooperação econômica, a OMC, pode ser considerado, diz a Autora, "como uma das principais realizações da Rodada Uruguai". ${ }^{38}$ Nesse sentido, como também enfatiza Geza Feketekuty, o GATS constitui o primeiro quadro jurídico abrangente para a liberalização global do comércio de serviços. Além desse quadro jurídico, “os países assumiram compromissos de acesso a mercados em setores e subsetores específicos e de tratamento nacional de serviços e prestadores estrangeiros em seus mercados". ${ }^{39} \mathrm{Na}$ visão de Jackson, o GATS foi

\footnotetext{
${ }^{34}$ Nome do edifício em que foram conduzidas as negociações em Washington.

${ }^{35}$ A França se opôs aos prazos e à abrangência do acordo sobre agricultura.

${ }^{36}$ A França também era contrária à inclusão de serviços audiovisuais no acordo sobre serviços. Ver CUNHA, Ciro Leal M. op. cit., p. 34. Os setores de serviços financeiros, telecomunicações básicas, transportes marítimos e profissionais, assim como os serviços relativos ao movimento de pessoas físicas, foram objeto de decisões ministeriais, as quais determinaram a continuação das negociações após a conclusão da Rodada Uruguai.

${ }^{37}$ Cf. MARCONINI, M. op. cit., p. 91.

${ }^{38}$ MERCADANTE, Araminta de Azevedo. op. cit., p. 414 e 417.

${ }^{39}$ FEKETEKUTY, Geza. Improving the architecture of the general agreement on trade in services. In STEPHENSON, Sherry M. (Org.). Services trade in the western hemisphere - Liberalization, Integration, and Reform. Washington: Organization of American States/Brookings Institution Press, 2000. p. 19. No original [livre tradução do autor]: “...the first comprehensive framework for the global liberalization of trade
} 
ainda relativamente mais longe ao incorporar os conceitos tradicionais do GATT (cláusula de nação mais favorecida, tratamento nacional e cronogramas de concessões) com as

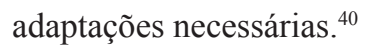

O mais importante, porém, da perspectiva dos países em desenvolvimento, é que as regras contidas no acordo de serviços da Rodada Uruguai são abertas, incompletas e flexíveis o suficiente para permitir uma progressiva liberalização do setor. Trata-se de acordo a ser completado por futuras negociações que poderão ser conduzidas em sintonia com as políticas de desenvolvimento traçadas pelos governos de cada um dos membros da OMC. Nesse tocante, prescreve o art. XIX, 2, do GATS:

2. O processo de liberalização respeitará devidamente os objetivos de políticas nacionais e o nível de desenvolvimento dos distintos Membros, tanto em geral, quanto nos diferentes setores. Haverá flexibilidade apropriada para que os diferentes países em desenvolvimento abram menos setores, liberalizem menos tipos de transações, aumentem progressivamente o acesso a seus mercados em função de sua atuação em matéria de desenvolvimento e, quando concedam acesso a seus mercados a prestadores de serviços estrangeiros, imponham condições destinadas à consecução dos objetivos referidos no artigo IV [Participação Crescente dos Países em Desenvolvimento].

Como sublinhado por Feketekuty, a difícil parte de reduzir as barreiras contidas nas regras governamentais existentes foi deixada amplamente para futuras rodadas de negociações. Os negociadores estavam cientes da necessidade de negociações subseqüentes e concordaram em retomá-las em 2000. A respeito, ficou estabelecido no art. XIX, 1, do GATS:

No cumprimento dos objetivos do presenteAcordo, os Membros manterão sucessivas rodadas de negociações, a primeira das quais até cinco anos após a entrada em vigor do Acordo Constitutivo da OMC, e periodicamente depois, com vistas a chegar a níveis progressivamente mais altos de liberalização. Tais negociações serão voltadas à redução ou à eliminação dos efeitos desfavoráveis das medidas sobre o comércio de serviços, como forma de assegurar o acesso efetivo aos mercados. Este processo terá por fim promover os interesses de todos os participantes, sobre a base de vantagens mútuas, e levar a um equilíbrio global de direitos e obrigações.

in services. In addition to the legal framework, countries negotiated national commitments on access to their markets in individual sectors and subsectors, and on the treatment of foreign services and service suppliers within the national markets".

${ }^{40}$ JACKSON, John H. op. cit., p. 307. 
Essas negociações também deveriam endereçar a questão das regras do GATS, principalmente as relativas a subsídios, salvaguardas, compras governamentais (licitações públicas), bem como a questão das normas concernentes aos requisitos e procedimentos de qualificação, padrões técnicos e condições para outorga de licenças e autorizações para prestação de serviços. ${ }^{41}$

As negociações do GATS na Rodada Doha (2001): semelhanças com a Rodada Uruguai

Como previsto no art. XIX, 1, do GATS, acima transcrito, uma nova rodada de negociações foi iniciada em janeiro de 2000. Essas negociações viriam a ser incorporadas, em 2001, à Agenda da Rodada Doha, em cuja Declaração ficaram assegurados prazos mais amplos para negociação de novas regulamentações, bem como para a definição de um cronograma para a apresentação de solicitações iniciais de liberalização de mercados (2002) e ofertas iniciais (2003). Algumas solicitações e ofertas pouco ambiciosas foram apresentadas tanto por países desenvolvidos como por aqueles em desenvolvimento antes e após a Conferência Ministerial de Hong Kong (2005), sem que resultassem em acordos. Além disso, antes da Conferência Ministerial de Hong Kong, algumas propostas de alteração da arquitetura original do GATS, bem como relativamente a parâmetros de implantação de regulamentação doméstica dos membros, foram formuladas por alguns países desenvolvidos, o que resultou em um aumento das divergências com os países em desenvolvimento. ${ }^{42}$

O que se nota, na prática, é que o avanço nas negociações sobre a liberalização do setor tem sido condicionado principalmente a um acordo no setor agrícola entre Estados Unidos, Comunidades Européias e o G-20.43 Os Estados Unidos relutam em reduzir o teto de subsídios domésticos, as Comunidades Européias em reduzir tarifas para ampliar o acesso a seu mercado, ambas reivindicações fundamentais do G-20. O G-20, uma coalizão de países emergentes e LDCs, liderada por Brasil e Índia e formada nos estágios finais de preparação para a Conferência Ministerial de Cancun, em 2003, também é pressionado a

\footnotetext{
${ }^{41}$ Ver FEKETEKUTY, Geza. Improving the architecture of the general agreement on trade in services. In STEPHENSON, Sherry M. (Org.). Services trade in the western hemisphere - Liberalization, Integration, and Reform. Washington: Organization of American States/Brookings Institution Press, 2000. p. 19-20.

${ }^{42}$ Ver CELLI JUNIOR, Umberto. Os acordos de serviços (GATS) e de investimentos (TRIMS) na OMC: Espaço para Políticas de Desenvolvimento. Revista do Centro Brasileiro de Relações Internacionais, v. 1, a. II, p. 8, 2007.

43 Além disso, ficaram mais evidentes ainda, após a fracassada reunião do G-4 (Estados Unidos, Comunidades Européias, Brasil e Índia) em Potsdan, na Alemanha, em junho de 2007, as divergências relativas ao corte das tarifas industriais consolidadas.
} 
abrir seus mercados agrícolas e industriais, o que deixa exposta sua fragilidade em face dos conflitos de interesses específicos de seus membros.

A semelhança desse contexto com o das negociações da Rodada Uruguai não é mera coincidência. Os Estados Unidos e as Comunidades Européias sempre relutaram em fazer concessões na área agrícola e continuam a fazê-lo. Na Rodada Uruguai, o G-10, liderado por Brasil e Índia, passou a vincular as negociações sobre serviços às negociações no setor agrícola. Desde a Conferência Ministerial de Cancun em 2003, o G-20, também liderado por Brasil e Índia, tem condicionado, quaisquer avanços em serviços na Rodada Doha a concessões no setor agrícola.

\section{Considerações Finais}

Se, de um lado, a articulação do G-10 na Rodada Uruguai proporcionou um acordo sobre serviços favorável aos países em desenvolvimento, já que o GATS dispõe de flexibilidade apropriada para que esses países abram menos setores, liberalizem menos tipos de transações e aumentem progressivamente o acesso a seus mercados tendo em vista sua atuação em matéria de desenvolvimento, de outro, a atuação do G-20, por mais crucial que tenha sido até o momento, pode não conduzir a um resultado satisfatório.

O comércio internacional de serviços tem crescido a uma taxa média anual de $9,0 \%$, totalizando, em 2005 , US\$ 2,4 trilhões, o que equivale a $23,2 \%$ do comércio mundial de bens que é de US\$ 10,39 trilhões. O comércio de serviços representa aproximadamente $80 \%$ do PIB dos países desenvolvidos e $60 \%$ do PIB brasileiro. No Brasil, o setor emprega mais de $50 \%$ da mão-de-obra e atraiu quase a metade de todos os investimentos estrangeiros. ${ }^{44}$

Assim, ainda que não haja dúvidas quanto à importância da agricultura para os países do G-20, principalmente para o Brasil, as negociações no setor de serviços não poderiam ser tidas como uma simples moeda de troca (trade off). O setor de serviços, por sua complexidade e importância, tem uma dinâmica própria de negociações que deve estar desatrelada das negociações do setor agrícola.

São Paulo, julho de 2007.

\section{Referências}

ABREU, Marcelo de Paiva. O Brasil, o GATT e a OMC: história e perspectivas. Política Externa, Rio de Janeiro, v. 9, n. 4, mar./maio 2001.

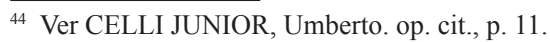


ABREU, Marcelo de Paiva. O Brasil na Rodada Uruguai do GATT: 1982-1993. In: FONSECA JÚNIOR, Gelson; CASTRO, Sérgio Henrique Nabuco de. Temas de política externa brasileira II. 2. ed. São Paulo: Paz e Terra, 1997. v. 1.

CARREAU, Dominique; JUILlARD, Patrick. Droit International Économique. 4. ed. Paris: L.G.D.J, 1998.

CELLI JUNIOR, Umberto. Os Acordos de Serviços (GATS) e de Investimentos (TRIMS) na OMC: espaço para políticas de desenvolvimento. Revista do Centro Brasileiro de Relações Internacionais (CEBRI), v. 1, a. II, 2007.

CUNHA, Ciro Leal M. da. A introdução do comércio de serviços na regulação multilateral do comércio: breve histórico. In: CELLI JUNIOR, Umberto, (Org.). Comércio de serviços na OMC. Curitiba: Juruá, 2005.

FEKETEKUTY, Geza. Improving the architecture of the general agreement on trade in services. In: STEPHENSON, Sherry M. (Org.). Services trade in the western hemisphere - Liberalization, Integration, and Reform. Washington: Organization of American States/Brookings Institution Press, 2000.

HOEKMAN, Bernard; MATTOO, Aaditya. Services, Economic Development and the Doha Round: Exploiting the Comparative Advantage of the WTO. Centre for Economic Policy Research (CEPR) - Discussion Paper Series n. 5628, abril de 2006, p. 01. Disponível em: <www.cepr.org/pubs/dps/ DP5628.asp>. Acesso em: 03 maio 2007.

JACKSON, John H. The World Trading System-law and policy of International Economic Relations. 2. ed. Cambridge: the MIT Press, 2002.

MARCONINI, Mário. O acordo geral sobre o comércio de serviços: o conceito e o regime. In: AMARAL JÚNIOR, Alberto do. OMC e o Comércio Internacional. São Paulo: Aduaneiras, 2002.

MATTOO, Aaditya; STERN, Robert. Trade in services - introduction and overview. In: Trade in Services Handbook. Washington: World Bank, p. 5 (material em preparação tornado disponível durante o "Trade in Services Internet Course", realizado de 25 de setembro a 30 de novembro de 2006).

MERCADANTE, Araminta de Azevedo. Harmonização em matéria de serviços e investimentos. In: CASELLA, Paulo Borba; MERCADANTE, Araminta de Azevedo. (Orgs.) Guerra comercial ou integração mundial pelo comércio? O Brasil e a OMC. São Paulo: LTr, 1996. 
SAUVÉ, Pierre. Been there, not [Quite] [Yet] done that: lessons and challenges in services trade. NCCR Trade Working Paper. Disponível em: <http://www.nccr-trade.org>. Aesso em: $1^{\circ}$ maio 2007.

STEWART, Terence. P. The Uruguay Round: a Negotiating History 1896-1992. Nova York: Aspen Publishers, 1996. v. 2. 